\title{
THE LEFT AURICULAR APPENDAGE IN MITRAL STENOSIS
}

\author{
BY \\ FLORENCE MCKEOWN \\ From the Institute of Pathology, Belfast \\ Received July 1, 1953
}

Since the introduction of the operation of mitral valvotomy much interest has been aroused in the histological changes found in biopsy specimens of the left auricular appendage. Some workers have recorded a high incidence of lesions resembling Aschoff nodules, and since these are found in patients in whom no rheumatic activity is apparent clinically, there has been much speculation as to their precise nature and significance. A review of the histological studies of rheumatic heart disease gives no indication of the frequency with which the appendage is involved in active carditis, nor of the morphology of the specific lesions in this site, since the appendage is not usually examined histologically. It is the purpose of this investigation, therefore, not only to record the findings in biopsy specimens of the left auricular appendage from patients who have had valvotomy, but also to study the appendage in patients who have died with mitral stenosis, in order to assess the full significance of the various lesions observed in this structure in patients suffering from chronic rheumatic heart disease.

\section{Auricular Appendages from Valvotomy CaSes}

Fifty-three appendages from patients who had mitral valvotomy were submitted for histological study, and in 24 lesions that were interpreted as Aschoff nodules were found. The nodules were observed within the endocardium or in the subendocardial zone, and in two cases in the myocardium of the appendage as well. The frequency of lesions in each appendage varied considerably, as also did their structure. In their most characteristic form they consisted of collections of large mononuclear and multinucleated cells, with abundant slightly basophilic cytoplasm. They were arranged in coronal or mosaic fashion in the vicinity of collagen fibre that had undergone fibrinoid change; a mantle of lymphocytes frequently surrounded the nodule, and the overlying endocardium showed much œdema (Fig. 1 and 2). Occasionally the Aschoff cells formed palisades within the endocardium between swollen collagen fibres, reproducing the banded appearance of rheumatic endocardial lesions described by McCallum (1924) and Gross (1935).

In some instances "doubtful" Aschoff bodies were noted; for example, nodules without fibrinoid change in the ground substance, and others in which the Aschoff cells, though maintaining a coronal arrangement, appeared shrunken and fibroblastic in character. Still others assumed the structure of a rather cellular spindle-shaped scar. Similar appearances have been described by other workers and have been referred to as " possible" or " probable" rheumatic lesions, or have been emphatically discounted as evidence of active rheumatism. Attention has been drawn by Gross and Ehrlich (1934) and McKeown (1945) to the cyclical changes that occur in the Aschoff nodule in the myocardium of the left ventricle. There, the nodule evolves initially from a focus of damaged collagen, about which the Aschoff cells become concentated; as healing takes place the change in the ground substance disappears, the Aschoff cells assume a spindle-shaped form, and finally a fibrillar scar results: this cycle may take 6-9 months to complete. Such changes have also been attributed to nodules in the endocardium of the left auricle by Gross and Ehrlich (1934) but are believed to be somewhat modified by the density of the tissue in which they occur. An attempt was therefore made in the present study to identify, if possible, the different phases of evolution of 


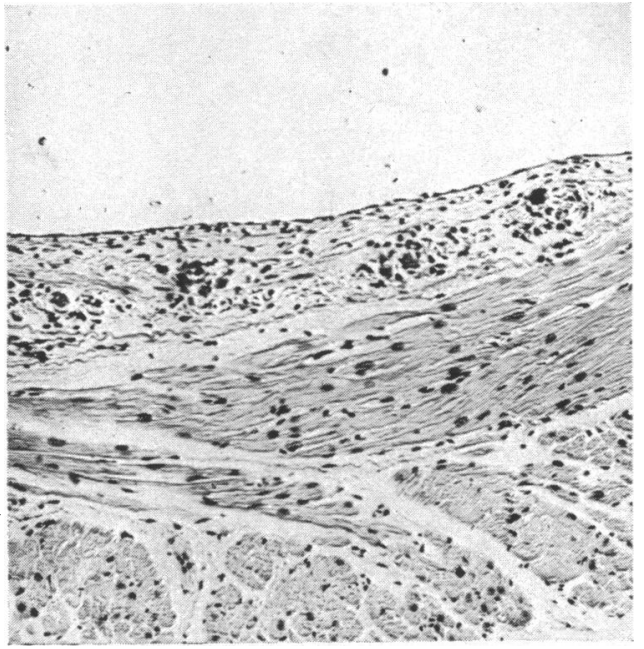

FIG. 1.-Low-power view of the appendage showing several Aschoff nodules in the endocardium $(x 64)$.

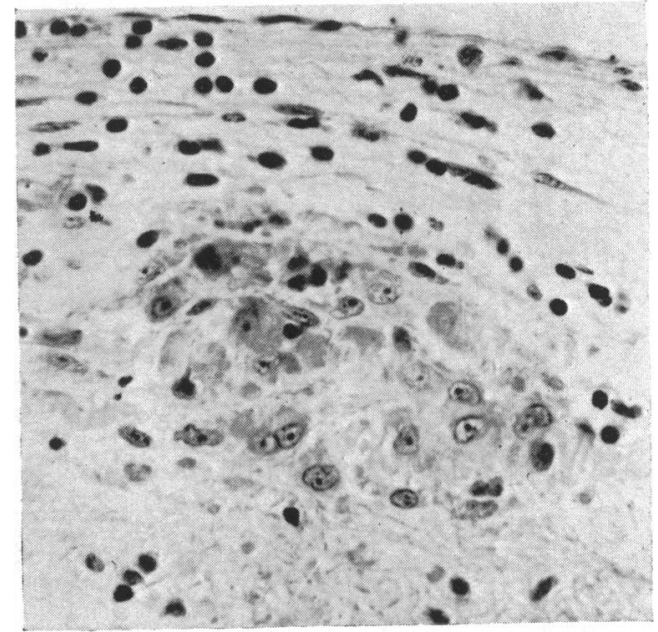

FIG. 2.-Endocardial Aschoff nodule, composed of large monc- and multi-nucleated cells arranged in coronal fashion around a focus of altered collagen $(\times 360)$.

the endocardial nodule, and to reconstruct in some measure, a life cycle comparable to that of the myocardial Aschoff nodule. The early exudative phase was recognized by the presence of marked fibrinoid degeneration in the ground substance and a sparse cellular reaction (Fig. 3), the fully developed nodule consisted of mature Aschoff cells with a coronal or mosaic arrangement (Fig. 4). The healing lesion showed elongation of the Aschoff cells (Fig. 5) and later the formation of a cellular spindle-shaped scar (Fig. 6). The stage of complete healing could not be recognized with certainty. These phases were best seen in the subendocardial zone where the connective tissue is loose and fibrillar. In the endocardium proper, where the ground substance is much more dense, the Aschoff nodules appeared to have a less distinctive life cycle. Acute lesions could be readily identified and had a fully characteristic structure, but regressing lesions often seemed to consist of

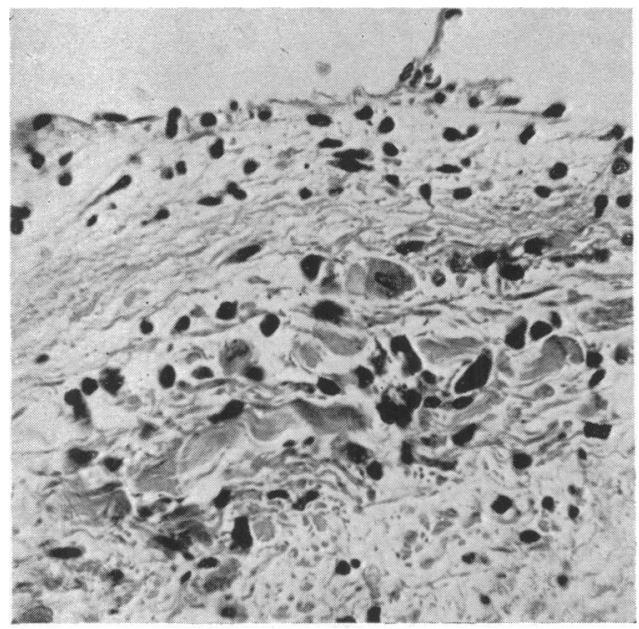

FIG. 3.-Aschoff nodule in early stage of development, showing marked fibrinoid change in ground substance and commencing cellular reaction $(\times 360)$.

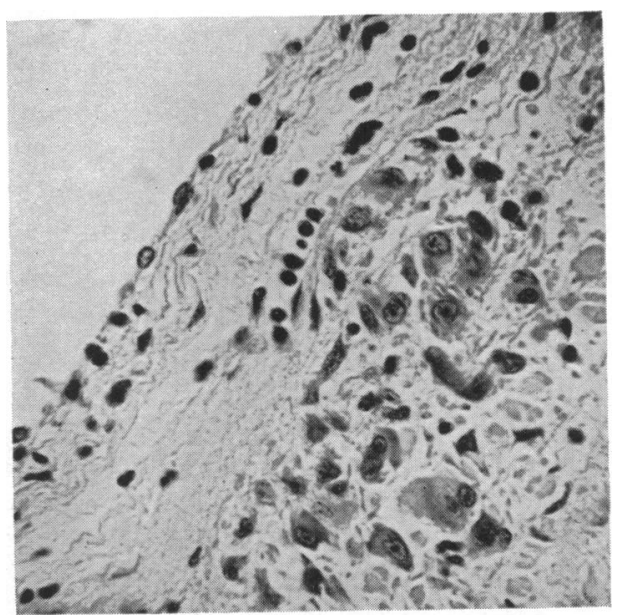

Fig. 4.-Fully developed nodule, with numerous large Aschoff cells in subendocardial zone $(\times 360)$. 


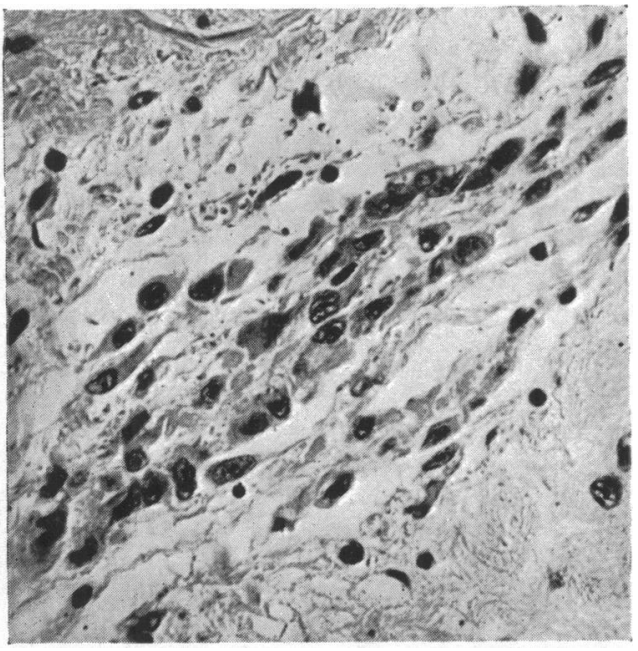

Fig. 5.-Polarizing nodule showing elongation of Aschoff cells $(\times 360)$.

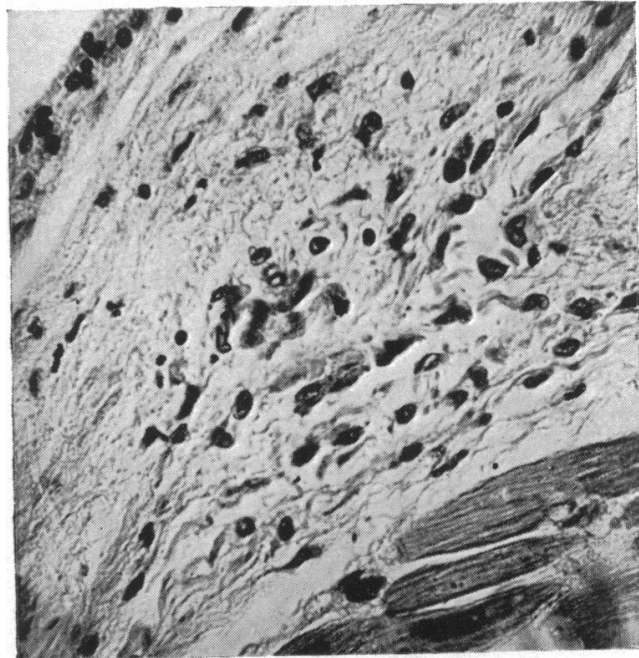

FIG. 6.-Aschoff nodule in later stage of healing, showing fibroblastic character or cells and formation of scar tissue $(\times 360)$.

radially arranged collections of darkly staining spindle-shaped cells, and had few of the distinctive features of healing lesions in other sites. The presence of such "doubtful" lesions has been stressed by many workers and has been one of the main reasons for disputing the specificity of the biopsy findings, but from the evidence available it is at least strongly suggestive that they represent nodules in which the phases of healing are less characteristic because of their situation in dense fibrous tissue.

As further evidence against the specificity of the biopsy lesions Enticknap (1953) has pointed out that the distribution of the nodules is unusual for rheumatic carditis in that they are almost invariably confined to the endocardium. Yet in 20 cases of acute rheumatism studied in this department only one had Aschoff nodules in the myocardium of the auricle, and in Gross' series (1935) of patients who had had repeated attacks of rheumatism and had histological evidence of activity post mortem only 1 in 28 had Aschoff nodules in the auricular myocardium. Thus the relative absence of myocardial nodules in the appendage of valvotomy cases is to be expected, if rheumatic lesions in this site are in any way comparable to those occurring in the wall of the left auricle. On histological grounds, therefore, the structure, evolution, and distribution of the lesions in biopsy specimens is essentially that of the specific Aschoff nodule of active rheumatic carditis.

The main reason for doubting the specificity of the biopsy findings is the complete lack of clinical signs of rheumatic activity in patients with positive lesions. It is generally accepted, however, that the absence of manifest symptoms does not preclude the existence of acute rheumatism. Many patients with mitral stenosis give no antecedent history of rheumatic fever. Some have suffered from one clinical attack only, and it is unlikely that this alone is responsible for the degree of valvular damage that ultimately develops. Repeated subclinical attacks of the type observed in biopsy specimens are much more likely to be responsible for the progression of the valvular lesion. There are many references to cases of mitral stenosis with unexpected evidence of rheumatic activity at autopsy, e.g. Rothschild et al. (1934), Gross (1935), Rogers and Robbins (1947), McKeown (1948), (1950), Graham et al. (1951), Pinniger (1951), and Waaler (1952). All such observations, in conjunction with the results of biopsy studies, stress the frequency of subclinical attacks of rheumatism, and emphasize the need for new clinical tests for assessing rheumatic activity.

The high incidence of Aschoff nodules in this biopsy series is in accord with the experience of other workers. Pinniger (1951) found nodules in 10 of 15 amputated appendages, Janton et al. (1952) 
in 14 of 88, Sabiston and Follis (1952) in 32 of 43, Waaler (1952) in 3 of 12, Kuschner et al. (1952) in 4 of 11, Biörck et al. (1952) in 6 of 18, Wylie (1952) in 4 of 9, and Enticknap (1953) in 29 of 71 cases. In Sabiston's series there appeared to be some correlation with the sedimentation rate as no patient having a raised sedimentation rate failed to show lesions. In the present series, however, only one patient with active endocarditis had a slightly raised rate $(16 \mathrm{~mm} . / 1 \mathrm{hr}$. $)$ and much higher readings were encountered in patients without carditis. Neither was there any relationship between the age of the patient and the occurrence of rheumatic activity.

It is not yet fully established whether these lesions in the appendage denote a widespread rheumatic carditis, but it is essential that this aspect of the problem should be investigated, for it may have an important bearing on the immediate and long-term prognosis. Four patients in Biörck's series (1952) died following operation and the autopsies in these cases were all completely in agreement with the biopsy picture, with no rheumatic activity detectable in any part of the heart. Ellis et al. (1951) found no other evidence of activity post mortem in two patients in whom biopsy specimens of the appendage taken a few hours before death showed Aschoff nodules. On the other hand, Pinniger (1951) confirmed the presence of active rheumatism in the myocardium of the left ventricle in one patient who had positive biopsy findings. Information of this nature should prove of value in assessing the significance of the biopsy lesions but will inevitably take time to accumulate since in any given valvotomy series the immediate mortality is low. For this reason a study of the appendage in post-mortem cases of mitral stenosis was undertaken, with the purpose of investigating the incidence of, and relationship between, active rheumatic lesions in this site and in other regions of the heart.

\section{The Auricular Appendage from cases of Mitral Stenosis (Post Mortem)}

Sections of the left auricular appendage were available for study in 92 cases of mitral stenosis on the post-mortem files of this department. The appendage was taken for examination either because it contained a thrombus, or because there was evidence of systemic embolization. More recently it has been taken routinely in all cases of mitral stenosis. There was a history of previous rheumatic fever in 45 patients. Clinically all were considered quiescent. Congestive heart failure was present during their terminal illness in 67 patients, 11 died directly from the effects of embolism, and the remainder from causes unrelated to their cardiac condition.

The left auricular appendage and a block that included the wall of the left ventricle, mitral valve, and left auricle were studied in each case, and the frequency of Aschoff nodules noted in these sites. In 70 hearts no rheumatic activity was detected in either the appendage or routine section. In 17 hearts Aschoff nodules were present in both sites, and in 5, nodules were noted in the myocardium of the left ventricle only (Table I.)

TABLE I

aschoff Nodes in Patients Dying with Mitral Stenosis

\begin{tabular}{c|c|c}
\hline $\begin{array}{c}\text { Mitral stenosis } \\
\text { No. of cases (92) }\end{array}$ & $\begin{array}{c}\text { Aschoff nodes in } \\
\text { L. A. appendage }\end{array}$ & $\begin{array}{c}\text { Aschoff nodes in } \\
\text { left ventricle }\end{array}$ \\
\hline 70 & - & $\overline{+}$ \\
17 & \pm & + \\
5 & - & + \\
\hline
\end{tabular}

In this somewhat selected series of clinically quiescent cases of mitral stenosis the total incidence of active rheumatic lesions is 24 per cent, and corresponds closely with the observations of Gross (1935) who recorded an incidence of 25 per cent in similar cases, and Pinniger (1951) who found 31 per cent of cases of mitral stenosis with definite Aschoff nodules. These findings lay further emphasis on the frequency of subclinical rheumatism. In an analysis of the positive cases the 
results tend to support the contention that Aschoff nodules in the left auricular appendage denote a generalized rheumatic carditis, since in 17 cases in which nodules were present in the appendage they were accompanied by similar lesions in the left ventricular myocardium. Their absence from the appendage in 5 cases in which they were noted in the wall of the left ventricle is in accord with the known distribution of rheumatic lesions in the heart, the routine section being taken close to the mitral posterior block which Gross et al. (1930) have demonstrated to be one of the sites of election of the rheumatic process. The highest incidence of lesions is found in this block and in a block of the tricuspid valve and septum. It might be added that in these 5 cases, only occasional nodules were seen and they were usually in the stage of polarization. In the cases in which active rheumatic lesions were found in both appendage and left ventricle the structure of the lesions in each site was similar, the same phase or phases of activity being represented. It was also observed that the frequency'of nodules in the appendage and in the myocardium of the left ventricle in each case corresponded closely, and in only one was the involvement heavy (Fig. 7 and 8).

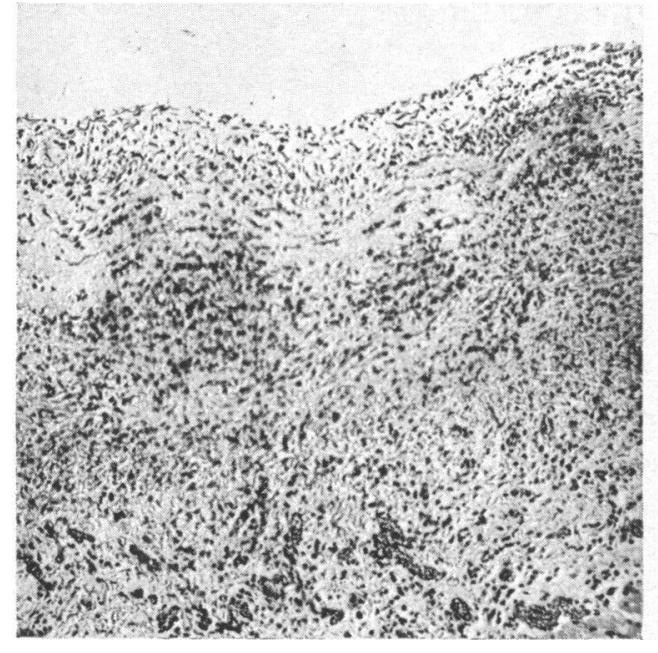

Fig. 7.-Appendage from post-mortem case of mitral stenosis, showing heavy involvement of endocardium by Aschoff nodules with a "banded" appearance ( $\times 145)$.

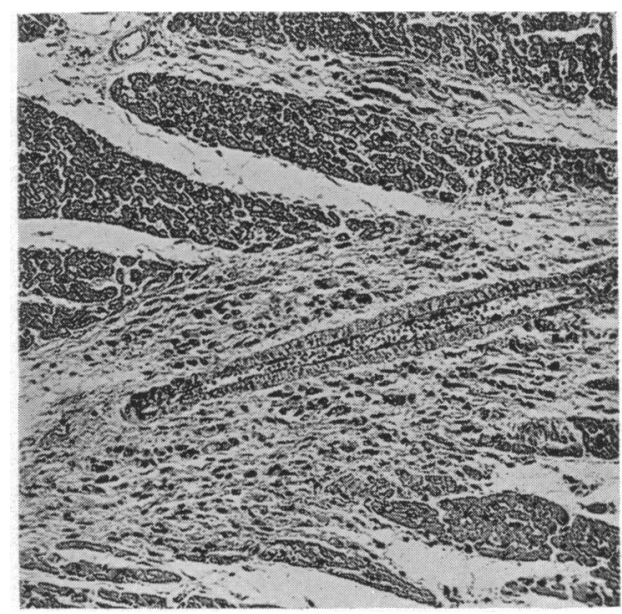

Fig. 8.-Myocardium of left ventricle, same case, showing multiple nodules in septa $(\times 80)$.

\section{CONCLUSIONS}

This combined study of biopsy and post-mortem sections of the left auricular appendage reveals a relatively high incidence of acute rheumatic lesions in this structure, in the complete absence of clinical signs of rheumatic activity. It is evident from analysis of post-mortem cases of mitral stenosis that a close correlation exists between the incidence and frequency of Aschoff nodules in the appendage and in the left ventricular myocardium. It would seem that the changes noted in the appendage reflect closely the state of the rest of the heart as far as rheumatic activity is concerned, except that occasionally the appendage may be spared when the rest of the heart is involved. That such a relationship exists should be of value in the interpretation of the significance of biopsy findings.

It is difficult to explain the absence of complications after operation in patients with histological evidence of active endocarditis. In some the rheumatic episode may be regressing, in others the relatively slight involvement of the appendage suggests a mild attack. Yet it is felt that active carditis in valvotomy patients may constitute a hazard and may precipitate or contribute in some measure to a fatal outcome. It is even possible that in the period before operation it may be one 
of the factors responsible for the aggravation of symptoms that renders operative treatment necessary.

It is to be hoped that the full significance of these subclinical episodes of rheumatic activity will ultimately be assessed by a prolonged clinical and pathological follow-up of all patients having a mitral valvotomy.

\section{SUMMARY}

The histological findings in 53 biopsy specimens of the left auricular appendage are recorded. In 24 , lesions were observed that showed the same distribution, structure, and evolution as the specific Aschoff nodule. A study of the appendage in 92 post-mortem cases of mitral stenosis is also presented, 17 cases showing Aschoff nodules in the appendage and in other parts of the heart. It is concluded that rheumatic nodules in the appendage denote a generalized rheumatic carditis, and the extent to which the appendage is affected reflects closely the degree of involvement of the left ventricle. The significance of these observations in relation to biopsy findings is discussed.

\section{REFERENCES}

Biörck, G., Winblad, S., and Wulff, H. B. (1952). Amer. Heart J., 44, 325.

Ellis, L. B., Bloomfield, R. A., Graham, G. K., Greenberg, D. J., Hultgren, H. N., Kraus, H., Maresh, G., Mebane, J. G., Pfeiffer, P. H., Selverstone, L. A., and Taylor, J. A. (1951). Arch. intern. Med., 88, 515.

Enticknap, J. B. (1953). Brit. Heart J., 15, 37.

Graham, G. K., Taylor, J. A., Ellis, L. B., Greenberg, D. J., and Robbins, S. L. (1951). Arch. intern. Med., 88, 532.

Gross, L. (1935). Amer. J. Path., 11, 711 .

-, and Ehrlich, J. C. (1934). Amer. J. Path., 10, 467.

_., Antopol, W., and Sacks, B. (1930). Arch. Path., 10, 840.

Janton, O. H., Glover, R. P., O’Neill, T. J. E., Gregory, J. E., and Froio, G. F. (1952). Circulation, 6, 321.

Kuschner, M., Ferrer, M. I., Harvey, R. M., and Wylie, R. H. (1952). Amer. Heart J., 43, 286.

MacCallum, W. G. (1924). Bull. Johns Hopkins Hosp., 35, 329.

McKeown, F. (1945). Ulster med. J., 14, 97.

- (1948). J. Obst. Gyn. Brit. Emp., 55, 50.

- (1950). Ulster med. J., 19, 68.

Pinniger, J. L. (1951). St. Thomas's Hosp. Rep., 7, 54.

Rogers, J., and Robbins, S. L. (1947). New Eng. med. J., 237, 829.

Rothschild, M. A., Kugel, M. A., and Gross, L. (1934). Amer. Heart J., 9, 586.

Sabiston, D. C., and Follis, R. H. (1952). Bull. Johns Hopkins Hosp., 91, 178.

Waaler, E. (1952). Acta. Path. Microbiol. Scand., Suppl. 93, 211.

Wylie, R. W. (1952). Bull. New York Acad. Med., 28, 106. 